\title{
O USO DE RECURSO DIDÁTICO PARA O ENSINO DE PORCENTAGEM: O RELATO DE UMA EXPERIÊNCIA NOS ANOS FINAIS DO ENSINO FUNDAMENTAL
}

\author{
THE USE OF DIDACTIC RESOURCES FOR TEACHING PERCENTAGE: THE REPORT \\ OF AN EXPERIENCE IN THE FINAL YEARS OF ELEMENTARY SCHOOL
}

\author{
Gabriel Santos de oliveira ${ }^{1}$ \\ Geiza Batista Pereira ${ }^{2}$ \\ Américo Junior Nunes da Silva ${ }^{3}$
}

RESUMO: Este relato de experiência é resultado de uma atividade de observação e inserção no espaço escolar, fomentado pela disciplina de Laboratório do Ensino de Matemática I, do curso de Licenciatura em Matemática do Campus VII da UNEB, Senhor do Bonfim - BA. O objetivo do presente trabalho é apresentar uma experiência de observação e inserção no espaço escolar dos anos finais do ensino fundamental e refletir sobre o quanto a mesma foi importante no processo de constituição da identidade docente. A atividade ocorreu ao longo de algumas semanas do segundo semestre de 2019 e totalizou 12 horas de inserção, da observação até a validação de material didático. A metodologia utilizada para a análise do espaço escolar foi a observação, seguido pela proposição de material didático para intervenção na realidade observada. Os resultados, após a realização da

I Estudante do Curso de Licenciatura em Matemática do Departamento de Educação da Universidade do Estado da Bahia, Campus VII. E-mail: gabriel_santosi407@hotmail.com.

${ }^{2}$ Estudante do Curso de Licenciatura em Matemática do Departamento de Educação da Universidade do Estado da Bahia, Campus VII. E-mail: geizzabatissta@gmail.com.

3 Professor do Departamento de Educação da Universidade do Estado da Bahia (Uneb - Campus VII) e docente permanente do Programa de Pós-Graduação em Educação, Cultura e Territórios Semiáridos - PPGESA (Uneb - Campus III). Coordenador do Núcleo de Pesquisa e Extensão (NUPE). Doutor em Educação pela Universidade Federal de São Carlos (UFSCar), Mestre em Educação pela Universidade de Brasília (UnB), Especialista em Psicopedagogia Institucional e Clínica pela Faculdade Regional de Filosofia, Ciências e Letras de Candeias (IESCFAC), Especialista em Educação Matemática e Licenciado em Matemática pelo Centro de Ensino Superior do Vale do São Francisco (CESVASF). Foi professor e diretor escolar na Educação Básica. Coordenou o curso de Licenciatura em Matemática e o Programa Institucional de Bolsas de Iniciação à Docência (Pibid) no Campus IX da Uneb. Foi coordenador adjunto, no estado da Bahia, dos programas PróLetramento e PNAIC (Pacto Nacional pela Alfabetização na Idade Certa). Participou, como formador, do PNAIC/UFSCar, ocorrido no Estado de São Paulo. Pesquisa na área de formação de professores que ensinam Matemática, Ludicidade e Narrativas. Integra o Grupo de Estudos e Pesquisas em Educação Matemática (CNPq/UFSCar), na condição de pesquisador, o Grupo Educação, Desenvolvimento e Profissionalização do Educador (CNPq/PPGESA-Uneb), na condição de vice-líder e o Laboratório de Estudos e Pesquisas em Educação Matemática (CNPq/LEPEM-Uneb) na condição de líder. É editor-chefe da Revista Baiana de Educação Matemática (RBEM) e coordenador do Encontro de Ludicidade e Educação Matemática (ELEM). E-mail: ajnunes@uneb.br. 
atividade, foram satisfatórios, tanto para os alunos quanto para os futuros professores, o que fortalece ainda mais a necessidade de incentivar esse tipo de atividade no espaço de formação inicial antes da realização do Estágio Curricular Supervisionado.

Palavras-chave: Ensino da Matemática. Material didático. Formação inicial.

ABSTRACT: This experience report is the result of an activity of observation and insertion in the school space, fostered by the discipline of Laboratory of Teaching of Mathematics I, of the Mathematics Degree course at Campus VII of UNEB, Senhor do Bonfim - BA. The objective of the present work is to present an experience of observation and insertion in the school space of the final years of elementary school and to reflect on how important it was in the process of constituting the teaching identity. The activity took place over a few weeks in the second half of 2019 and totaled 12 hours of insertion, from observation to validation of teaching material. The methodology used for the analysis of the school space was observation, followed by the proposition of didactic material for intervention in the observed reality. The results, after the activity, were satisfactory, both for students and for future teachers, which further strengthens the need to encourage this type of activity in the initial training space before the Supervised Curricular Internship.

Keywords: Mathematics teaching. Didactic material. Initial formation.

\section{INTRODUÇÃO}

É inegável que a Educação tem papel fundamental no desenvolvimento Socioeconômico de uma sociedade. Como se pode observar ao redor do mundo, onde se prioriza uma educação de qualidade, desfruta-se de uma sociedade com um maior IDH (índice de desenvolvimento humano). Uma educação de qualidade, com planejamento e estrutura, pode ser um divisor de águas, no sentido de qualidade de vida dos estudantes e de toda a sociedade.

Diante disto, é de suma importância que nós, futuros educadores, tenhamos o conhecimento do dia a dia de uma sala de aula, mas não agora como alunos, como foi a maior parte de nossa trajetória, mas sim, de observadores da relação do aluno com professores e escola, nos colocando no lugar de futuros professores. Com esse pensamento fomos incentivados pelo docente da disciplina Laboratório do Ensino da Matemática I da UNEB, Campus VII - Senhor do Bonfim-BA, para nos inserirmos em um espaço escolar para realização de observação em sala de aula, proposição e validação de material didático no final das nossas análises e observações.

Desta forma, este relato de experiência tem por finalidade, apresentar as experiências da observação em uma sala de aula de matemática dos anos finais do ensino fundamental. A atividade foi realizada em uma escola pública de um município da região norte do estado da Bahia e objetivou identificar as dificuldades enfrentadas pelos alunos e professores no processo de ensino e aprendizagem da matemática e, enquanto discentes em licenciatura em matemática, nos aproximar do nosso futuro trabalho. Foi proposta também, ao final das observações, propor e validar um material didático construído com base nos assuntos estudados em sala de aula, e com isso ajudar os 
alunos com dificuldade de aprendizado a buscarem outras formas de aprender, além do método tradicional.

Este texto foi divido em quatro seções que, em nosso entendimento, se articulam entre si e ajudam a entender a experiência vivenciada. São elas: I) Introdução - onde relataremos o contexto inicial de realização da atividade; 2) Relato das observações - onde expomos nossas experiências com a atividade desenvolvida e refletimos sobre os reflexos da mesma para a nossa formação; 3) Relato da construção e validação do jogo - onde tratamos das trajetórias para a proposição e validação do material didático; 4) Considerações finais - apresentamos nossas conclusões sobre as análises feitas em sala e, como essa experiência contribuiu em nosso constituir-se profissionais.

\section{Relato das observações}

As observações foram realizadas numa turma do $7 .^{\circ}$ ano do ensino fundamental de uma escola pública de um município da região norte do estado da Bahia; em uma sala na qual a professora nos recebeu gentilmente. A classe possuía 22 alunos, 16 do sexo masculino e 6 do sexo feminino, com idades que variavam de 14 e 19 anos.

No nosso primeiro dia de observação fomos apresentados a turma pela professora. Notamos que não houve, por parte dos alunos, estranhamento com a nossa presença. Analisamos a estrutura da sala e vimos que não tinham cadeiras adequadas e em bom estado, nem tão pouco ventilação ou luz apropriada. Surpreendeu-nos o fato das paredes estarem todas rabiscadas com frases de baixo calão e o quadro branco perfurado por algum estilete ou faca. A professora gentilmente nos comunicou que não era formada na área de Matemática e que há 20 anos havia se formado em Letras. Relatou ainda que após aprovação no concurso foi direcionada para a área de Matemática. Isso nos surpreendeu, uma vez que há exigência legal para que o exercício da docência aconteça por professores que possuam formação apropriada. Vejamos o que Correia e Silva (2020, p. o6) destacaram a esse respeito:

Infelizmente, professores sem formação na área lecionando a disciplina ainda é uma realidade em muitas escolas em nosso estado. Embora essa situação esteja muito distante de ser desejável, comumente, "é a única opção possível”, dadas as condições de trabalho e a política educacional de muitos municípios. Entendemos, partindo do que apresenta Shulman (2005), a importância de que o professor tenha, para sua prática, compreensão da estrutura da matéria ensinada e de sua organização pedagógica. No entanto, a reflexão parece desconhecida por alguns setores/gestores públicos, que trabalham sob a lógica de que "ter um professor que não seja da área é melhor do que não ter professor algum" (CORREIA; SILVA, 2020, p.o6) 
Isso que destacamos anteriormente nos levou a pensar sobre a quantidade de vezes que tivemos, em nossa época de estudantes da Educação Básica, professores sem formação específica lecionando determinadas disciplinas. Sabemos que, assim como foi para a professora da turma observada, muitos docentes são levados a assumirem componentes curriculares diferentes de sua área de formação, como forma de complementar sua carga horária ou na ausência de outros profissionais. Hoje, enquanto futuros professores, entendemos as implicações dessas questões para os movimentos de ensino e aprendizagem da Matemática e advogamos que os gestores públicos garantam a todos os estudantes professores com formação específica.

Destarte, esse problema apresentado anteriormente, por exemplo, prejudica a vivência do currículo, uma vez que, como aponta as Diretrizes Curriculares da Bahia, nos "dias atuais, há uma grande necessidade de que os(as) professores(as) desenvolvam competências profissionais para preparar os alunos em uma formação critico social.” (BAHIA, 2019, p. 312). Mas como isso será possível, particularizando essa discussão para as competências a serem desenvolvidas na área de Matemática, se a própria professora não possuía formação adequada?

Nesse mesmo dia da primeira observação ela, a professora, passou uma atividade no livro para eles fazerem na sala de aula. Fato intrigante foi o de não os ajudar nem direcionar como seria realizada essa atividade. Assim, no decorrer da aula, eles copiaram do livro as questões. Segundo o Documento Curricular da Bahia orienta

\begin{abstract}
Deve-se buscar, então, autonomia intelectual dos alunos, por meio de atividades planejadas pelo professor, pra promover o uso de diversas habilidades de pensamento, como interpretar, analisar, sintetizar, classificar, relacionar e comparar, como possibilidade de desenvolver o processo de aprendizagem que foca uma formação crítica de estudantes e profissionais voltada para uma inserção consciente no mundo cultural e social. (BAHIA, 2019, p. 312).
\end{abstract}

Nesse sentido, portanto, o papel do professor é importante no sistematizar de uma proposta que consiga articular a formação desse perfil apontado no Referencial Curricular da Bahia. Mas voltando e mesmo sendo repetitivo cabe destacar que para isso é importante ter formação adequada. O planejamento de aulas, como evidenciado por Silva et al. (2014), alcançara mais facilmente a sua dimensão política e pedagógica, quando construído por professores com formação apropriada.

Destarte, sabemos que são muitos os conhecimentos necessários à docência mobilizados para planejar, executar e avaliar os planos de aula, ainda de acordo com os autores referenciados anteriormente e concordando com Shulman (2005). Não queremos hierarquizar esses conhecimentos e dizer que este ou aquele é mais importante, isso não; mas precisamos evidenciar que ao professor cabe ensinar matemática e, por isso, o conhecimento do conteúdo e pedagógico do conteúdo é necessário; o que reforça, mais uma vez, a nossa defesa a uma formação na área. 
No dia seguinte ela recolheu os cadernos para ver quem havia respondido os exercícios apresentados na aula anterior. Logo depois corrigiu as questões no quadro e finalizou a aula fazenda a chamada dos alunos e avisando que na próxima aula ela traria um jogo de quebra-cabeça da multiplicação, onde eles deveriam efetuar a multiplicação e associar a parte correspondente às peças e assim ir montando o quebra-cabeça. Como encaminhamento pediu para eles estudarem a tabuada.

No dia da realização do jogo quebra-cabeça da multiplicação notamos a dificuldade que os alunos tinham em multiplicar 5 vezes 7 , por exemplo, e outros valores parecidos. Nossa estimativa foi que cinquenta por centos dos alunos, apresentaram dificuldades na vivência do proposto pela professora. Nesse mesmo dia nos deparamos com a situação de que a professora tinha preferência por determinados alunos e a outros, tão pouco, ela os ajudava. Esse fato nos remeteu que tais alunos excluídos eram repetentes e que no decorrer do ano letivo frequentavam pouquíssimas vezes as aulas de Matemática, afirmação essa dada pela professora. Nessa situação pensamos: "não seria o inverso? Não são esses alunos, com dificuldades, que precisam de mais atenção e acompanhamento?”. Entendemos necessário, concordando com Silva, Nascimento e Muniz (2017), um olhar mais sensível e atento do professor que ensina matemática as produções dos estudantes.

Na semana seguinte, ao chegarmos à escola percebemos que a professora já havia passado a atividade para fazer na sala de aula. Notamos que em nenhum momento os alunos tiravam dúvidas com a professora e que nem havia entre eles um bom diálogo. Alguns alunos nem o caderno levavam para escola. Logo após eles responderem o proposto, ela colocou as respostas das questões no quadro e esse fato nos intrigou, pois, não houve uma explanação sobre o conteúdo e nem um direcionamento de como resolver os problemas dados e/ou se os alunos fizeram corretamente.

Sobre o ponto que destacamos anteriormente, a avaliação, achamos prudente considerar que ela precisa assumir um caráter formativo e que o erro, como evidenciam Silva e Souza (2014), assuma um lugar importante e parte do processo de construção do conhecimento matemático. Como asseverou D'Ambrosio (1993), ao ato de matematizar cabe o prazer da descoberta e a liberdade na construção de respostas. Isso, que propõe o autor, só é possível se o erro assumir outro lugar e, nesse sentido, o professor precisa assumir uma postura diferente.

\section{Relato da experiência de construção do material didático}

Depois de algumas observações das aulas, notamos que os assuntos estudados pelos alunos eram Porcentagem e Resolução de Problemas. Após observar com mais calma, notamos que a maioria 
dos estudantes tinha dificuldade de compreender o assunto (porcentagem). Entretanto, partindo de nossos encontros presenciais para discussão durante a disciplina na universidade, percebemos que esta dificuldade enfrentada pelos observados por nós, não é exclusividade desta sala, mas sim, um problema enfrentado por muitas outras salas de aula de escolas públicas do país, como a dos nossos colegas, que não contemplam uma estrutura necessária para uma melhor aprendizagem da Matemática; e nem criam para os alunos uma relação entre a Matemática e a vida cotidiana.

O que percebemos é que este problema, como evidenciado por Silva (2014), muitas vezes, é estrutural, e, infelizmente, a partir de nossas observações, nos remete a má formação dos professores que ensinam matemática nas escolas. Desta forma, Santos (2002, p. 85) afirma que "quando avaliamos o ensino que recebemos ou que praticamos, temos a sensação de contemplar uma obra que necessita ser restaurada, pois, no estado em que a vemos, temos uma vaga ideia do que foi ou deveria ser".

Com tudo isso em mente, pensamos em pesquisar materiais didáticos que facilitassem a melhor compressão do assunto pelos alunos, mas com a ideia de um material de fácil compreensão, pois percebemos que a dificuldade era grande, e não queríamos afastar os alunos do conhecimento matemático. Nessa direção, partindo do que nos apresenta Muniz (2016, p. 20), "a necessidade de jogos didáticos nas aulas de matemática apresenta-se cada vez mais presente no atual discurso educacional brasileiro, como uma forma prazerosa e lúdica de aprendizagem matemática”.

Depois de muita pesquisa, encontramos na internet um jogo que, no nosso entender, era de fácil acesso e ajudaria os alunos da sala a compreenderem melhor o assunto de Porcentagem. Tratase do jogo denominado "Jogo de tabuleiro das porcentagens" que pretende, calcular porcentagem por atividade lúdica.

Escolhemos esse jogo "tabuleiro das porcentagens" por ele se encaixar no modelo de material que queríamos apresentar aos alunos, por entender que para essa realidade observada especificamente ele contribuiria sobremaneira. Outro motivo é que o jogo não é muito complicado pra quem não domina os conhecimentos sobre porcentagem.

\section{I Materiais para a construção do jogo "tabuleiro das porcentagens"}

a) I dado com as porcentagens - $25 \%, 50 \%$ e $75 \%$;

b) I dado com os valores - 80, 100, 160, 200, 240 e 300;

Imagem or - Dados construídos

4 o jogo a que nos referimos nesse relato foi construído a partir da consulta ao seguinte site: https://docplayer.com.br/I717437II-Jogo-tabuleiro-de-porcentagens.html 


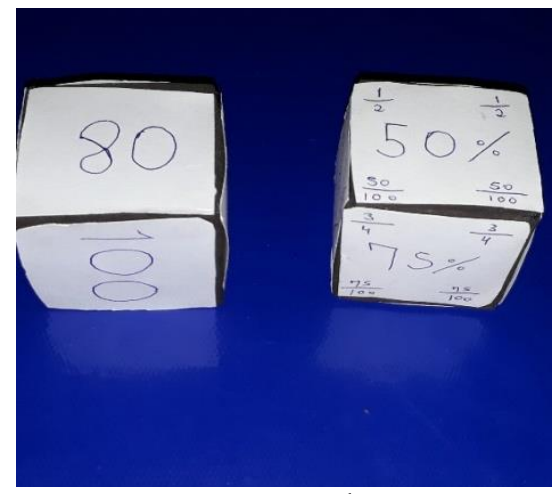

Fonte: arquivo dos autores

c) I tabuleiro adaptado;

Imagem 02 - Tabuleiro adaptado

\begin{tabular}{c|c|c|c|}
150 & 40 & 25 & 50 \\
\hline 120 & 225 & 20 & 180 \\
\hline 80 & 60 & 75 & 100 \\
\hline
\end{tabular}

Fonte: Arquivo pessoal dos autores

d) Io marcadores - 5 para cada equipe. (usamos io tampas de garrafa pet., 5 de duas cores diferentes).

\subsection{Regras do jogo "tabuleiro das porcentagens":}

i) $\mathrm{O}$ jogo deve ser jogado em duas equipes;

ii) Cada equipe, na sua vez, joga os dois dados, o da porcentagem e outro do número inteiro e efetua os cálculos necessários, e se acertar coloca o seu marcador no tabuleiro;

iii) Ganha o jogo a equipe que conseguir primeiro colocar no tabuleiro os 5 marcadores. OBS: vale colocar dois ou mais marcadores na mesma casa do tabuleiro.

5 lembrando que as informações desse jogo foram consultadas na internet, no site: https://docplayer.com.br/1717437II-Jogo-tabuleiro-de-porcentagens.html 


\section{Validação do material didático}

No último dia de observação, fomos até a sala apresentar o jogo aos alunos. Geralmente, não encontramos dificuldades em apresentar o material, pelo contrário, tivemos o apoio tanto da professora quanto dos alunos. Quando falamos em apresentar algo diferente, isso chamou a atenção dos alunos e prendemos a atenção deles, e isso na nossa visão é algo altamente positivo, pois, como destaca Muniz (2016, p. 19) "só aprende, em especial matemática, quem se permite jogar". O jogo pode despertar o interesse dos alunos a buscar aprender além do método expositivo. Além disto, prender a atenção dos alunos não, é algo fácil para um docente que ensina matemática, tendo em vista, que a aula de matemática sempre foi vista como uma aula chata e cansativa.

Outro ponto importante é a participação da docente durante toda a vivência do jogo com os estudantes. Isso, de certa forma, contribui para o que Silva e Sá (2014) chamam de formação lúdica. A professora, na oportunidade e em contato com o material e a experiência, é levada a pensar sobre o uso desses materiais e o lugar que ele ocupa no processo de aprendizagem. Importante destacar, ainda segundo Silva e Sá (2014) e Silva (2014), que ao professor cabe uma formação específica para entender e lidar com essa categoria de material.

Sendo assim, a sala foi dividida em dois grupos, uma equipe com a maioria de meninos, e outra com a maioria de meninas. E assim foi denominado, meninas contra meninos. Vale destacar que esse critério foi escolhido pelos próprios estudantes.

Geralmente, às duas equipes não apresentaram dificuldades em resolver a carta de 50\% com um número inteiro qualquer. Isso se deu pelo fato de $50 \%$ ser metade, ou seja, muitos estavam apenas dividindo o número inteiro por 2. Mas o meu questionamento era, então, porque não aplicar a mesma lógica com a carta de $25 \%$ e $75 \%$. Deste modo, quando saiu à carta de $25 \%$ resolvemos demonstrar no quadro da sala que $25 \%$ nada mais é que dividir o número inteiro por 4 . Da mesma forma resolvemos demonstrar a carta de $75 \%$, entretanto, está ficou um pouco mais difícil a compreensão por parte dos alunos. Mas conseguimos explicando que $75 \%$ nada mais é que $50 \%$ mais $25 \%$. Então explicamos que $75 \%$ é o mesmo que dividir o 100\% em 4 partes iguais (4 partes de $25 \%$ ) e somar 3 destas partes, totalizando assim $75 \%$.

Logo após a explicação com o desenrolar do jogo, o número de acertos da carta de 75\% foi um pouco maior, porém na nossa visão não foi o suficiente, ainda tiveram muitos erros. Sendo assim, como afirma Lorenzato "por melhor que seja o Material didático, não é garantia de um bom ensino e funciona apenas como meio auxiliar, e não substitui o professor" (LORENZATO, 2016, p. 27). São outros inúmeros fatores que ajudam a facilitar a aprendizagem em matemática, não podemos pensar que somente a aula expositiva, o jogo ou qualquer outra forma de ensinar, como algo milagroso que 
vai resolver todos os problemas, mas sim um conjunto de fatores que se encaixaram como um mosaico para então facilitar o aprendizado matemático.

A partida ocorreu por volta de 25 minutos e no final a equipe vencedora recebeu seu prêmio: uma caixa de bombons. No fim a disputa entre as equipes ficou apenas no decorrer da atividade, pois no fim a equipe vencedora decidiu dividir o prêmio com os demais colegas de classe.

\section{Considerações finais}

Após a finalização da atividade em sala, ficaram algumas reflexões a serem feitas. Para nós, enquanto futuros professores, a atividade foi de grande importância, pois além de nos aproximar de uma sala do ensino fundamental nos abriu os olhos para realidades que quando somos apenas estudantes nos passam despercebidas, como, por exemplo, o descaso com a educação pública no país.

Geralmente, como observado, tanto a estrutura física quanto o ensino são sucateados e isso nos leva a refletir se vamos mesmo conseguir mudar essa realidade para os nossos estudantes. Todo mundo tem o direito de aprender, mas para isso acontecer é importante que o estado ofereça condições adequadas e que, também, se tenha uma formação por excelência para que os professores consigam ajudar os alunos.

Em relação à proposição e validação do jogo: na nossa visão a aplicação foi positiva, pois todos os alunos da classe realizaram a atividade e não, percebemos alguém incomodado com a realização do proposto, pelo contrário, percebemos uma vontade de vencer a competição sadiamente e de sanar as dificuldades quando elas existiam. Nós não mudaríamos nada no jogo, pois a aplicação foi positiva, o que poderíamos ter melhorado era dividir melhor a classe, levar mais material (dados e tabuleiros) para que todos os alunos pudessem estar em contato mais tempo com o jogo, para despertar mais o interesse.

\section{Referências}

BAHIA. Documento Curricular Referencial da Bahia para Educação Infantil e Ensino Fundamental - Superintendência de Políticas para Educação Básica. União Nacional dos Dirigentes Municipais de Educação. Bahia Salvador: Secretaria da Educação, 2019.

CORREIA, V. C. P; SILVA, A. J. N. O estágio e a formação de professores de matemática. Revista Brasileira de Educação Básica. Belo Horizonte, Ano 5, n. 17, 2020.

DA SILVA, A. J. N; DO NASCIMENTO, A. M. P; MUNIZ, C. A. O Necessário Olhar do Professor sobre a Produção Matemática das Crianças nos Anos Iniciais. Educação Matemática em Revista, p. 48-55, 2017. 
D’AMBROSIO, Beatriz S. Formação de Professores de Matemática para o Século XXI: o Grande Desafio. Pro-Posições. v. 4 n.I. 1993.

LOREZANTO, S. O laboratório de ensino de matemática na formação de professores / Sergio Lorenzato. $3^{\text {o }}$ ed. - Campinas, SP: Autores associados, 2010. (Coleção formação de professores).

MUNIZ, C. A. Educação Lúdica da Matemática, Educação Matemática Lúdica. In: SILVA, A. J. N; TEIXEIRA, H. S (Org.). Ludicidade, formação de professores e educação matemática em diálogo - Io ed. - Curitiba, Appris, 2016.

SANTOS, V. M. O Desafio de Tornar-se Professor de Matemática. In: NUANCES: estudos sobre educação - ano VIII, nº 08 - setembro de 2002.

SHULMAN, L. S. Conocimiento y enseñanza: fundamentos de la nueva reforma. Profesorado. Revista de Currículum y formación del profesorado, v. 9, n. 2, p. 1-30, 2005. Disponível em: http://www.ugr.es/ recfpro/Rev92.html. Acesso em: o6 fev. 202I.

SILVA, A. J. N; SÁ, A. V. M; Doutores da aprendizagem: Revivendo a criança adormecida em cada educador. In: Sá, Antônio Villar Marques; Silva, Américo Júnior Nunes da, Braga, Maria Dalvirene; Silva, Onã (Orgs.). Ludicidade e suas interfaces. Brasília: Líber Livro, 2013.p. 63-77.

SILVA, A. J. N.; SOUSA, I. S. (Orgs.). A formação do professor de matemática em questão: reflexões para um ensino com significado. Jundiaí: Paco Editorial, 2014

SILVA, Américo Junior Nunes da. Formação lúdica do futuro professor de matemática por meio do Laboratório De Ensino. 2014. 196f. Dissertação. (Mestrado em Educação) - Universidade de Brasília, Brasília, 2014.

SILVA, A. J. N; SOUSA, I. S; BARROS, S. S; ALMEIDA, J. D. S. O Professor de Matemática e o Ato de Planejar: Há Unicidade entre a Dimensão Política e a Dimensão Pedagógica? In: SILVA, A. J. N; SOUSA, I. S. A Formação do Professor de Matemática em Questão: Reflexões para um Ensino com Significado, Jundiaí: Paco Editorial. 2014. 